\title{
MOTIVASI DALAM ASPEK PEMILIHAN PROFESI SEBAGAI KARYAWAN BANK SYARIAH X SURABAYA (Studi Kasus Rekrutmen Tahun 2012)
}

\author{
Eka Rizky Andriani \\ Mahasiswa Program Studi S-1 Ekonomi Islam - Fakultas Ekonomi dan Bisnis - Universitas \\ Airlangga \\ Email: Ekarizky_andriani@yahoo.com
}

Siti Inayatul Faiza

Departemen Ekonomi Syariah - Fakultas Ekonomi dan Bisnis - Universitas Airlangga Email: naya_viencha@yahoo.co.id

\begin{abstract}
Developing the rapid syariah banking along with increasing number of employee who is recruited by syariah banks motivate human resources existing to choose profession as employees in syariah banks.

This research aims to know the basic considerations motivation for choosing a profession as an employee of Bank Syariah X Surabaya. The approach used in this research is qualitative approach with eksplanatoris case study. . Data collection is done by gathering documents, interviews, direct observation, and physical devices toward employee recruitment of Sharia Bank X Surabaya 2012. The techniques of analysis conducted is making an explanation.

The results obtained that there are various forms of motivation shown by each employee who push their chosen profession as an employee of Bank Syariah $X$ Surabaya. Then, that motivation is classified and described according to the theory of motivation based on Islam, Khaliq Ahmad namely The Need Theory, Instincts and Innate Biological Determinants for Behaviour, Incentives (External Stimuli), Commitment (Sincere), and Motivated Personality which is separated as Nafs Ammarah, Nafs Lawwamah, and Nafs Mutmainnah.

Key words:islamic Motivation, employees, syariah bank, profession, recruitment

Dengan semakin berkembangnya

\section{PENDAHULUAN}

\section{A. Latar Belakang}

Semakin pesatnya perekonomian Islam di Indonesia ditandai dengan semakin meningkatnya lembaga kevangan syariah, tidak terkecuali dengan bank syariah yang terus bertambah jumlahnya dari tahun ke tahun. Perkembangan lembaga kevangan syariah tercatat meningkat, pada Oktober 2012 terdapat 11 buah bank umum syariah (BUS) dan 24 buah unit usaha syariah (UUS).

perbankan syariah di Indonesia dan semakin banyaknya karyawan yang bekerja di bank syariah sehingga karyawan- karyawan tersebut memiliki berbagai macam motivasi yang mendorong mereka memilih bekerja sebagai karyawan bank syariah. Terdapat banyak hal yang dapat memotivasi seseorang untuk motivasi seseorang bekerja sebagai karyawan di bank syariah untuk mencapai tujuan dan kepuasan, motivasi tersebut dapat berupa tingginya gaji karyawan, rendahnya persaingan pada bank syariah sehingga mendapat promosi
\end{abstract}


jabatan lebih cepat, motivasi kenyamanan di bidang psikologis karena tidak melanggar syariat Islam. Motivasi dapat diartikan sebagai dorongan individu untuk melakukan tidakan karena mereka ingin melakukannya. Apabila individu termotivasi, mereka akan membuat pilihan yang positif untuk melakukan sesuatu karena dapat memuaskan keinginan mereka Rivai (2009:861). Seperti pernyataan beberapa karyawan yang bekerja di Bank Syariah $X$ memilih profesi sebagai karyawan di bank syariah bahwa mereka bekerja selain untuk mencari nafkah juga termotivasi untuk beribadah kepada Allah. Islam memandang motivasi ini sebagai sesuatu yang penting. Seperti yang tercantum dalam surat Al-Baqarah (2):148

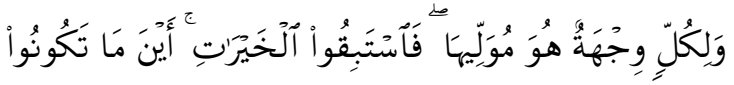

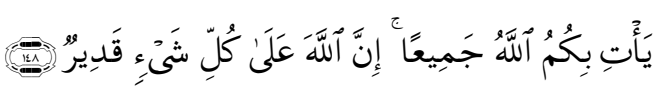

walikullin wijhatun huwa muwalliihaa faistabique alkhayraati aynamaa takuunue ya/ti bikumu allaahu jamii'an inna allaaha 'alaa kulli syay-in qadiirun

Artinya: "dan setiap umat mempunyai kiblat yang dia menghadap kepadanya. Maka berlomba-lombalah kamu dalam hal kebaikan. Dimana saja kamu berada, pasti Allah akan mengumpulkan kamu semuanya. Sungguh Allah Maha Kuasa atas segala sesuatu."
Dalam ayat di atas mengisyaratkan tuntunan agar hamba-hamba Allah yang beriman senantiasa berlomba-lomba dalam hal kebajikan. Allah hendak membentuk mentalitas dalam pribadi orang yang beriman untuk bersemangat dan termotivasi untuk melakukan berbagai kebaikan (Rivai, 2009:858).

\section{LANDASAN TEORI}

\section{A. Pengertian Sumber Daya Manusia}

Menurut Rivai (2009:17) sumber daya manusia adalah seseorang yang mau siap, mau dan mampu memberi sumbangan terhadap usaha pencapaian tujuan organisasi. Selain itu sumber daya manusia merupakan suatu unsure masukan input yang bersama dengan unsur lainnya, seperti modal, bahan, mesin dan metode/teknologi di ubah melalui proses manajemen menjadi keluaran (output) berupa barang dan jasa dalam usaha mencapai tujuan perusahaan. Pengertian Manajemen Sumber Daya Manusia (MSDM) dalam Islam

Rivai (2009:1031-1032) menjelaskan dari sebelas ayat di atas tampaklah ciri-ciri manusia yang beruntung dan akan mewarisi surge firdaus adalah orangorang yang memiliki :

a. Kecerdasan spiritual yakni sangat sadar akan adanya kehidupan yang kekal selepas dunia dan selalu mengaitkan sepak terjangnya dengan kekuatan yang Maha Sempurna yakni 
kekuatan transedental Allah SWT. Sehingga begitu ia selalu beriman.

b. Kecerdasan akhlak yang menempatkan sebagai manusia yang saleh pribadinya serta di gambarkan dengan khusyuk dalam shalatnya, memelihara kemaluannya, dan memelihara shalatnya. Selain itu, ia saleh dalam kehidupan sosialnya yang di gambarkan dengan menunaikan zakat. la sangat sadar sehingga tidak melampaui batas dalam kehidupannya.

\section{B. Pengertian Karyawan}

Hasibuan (2007:117) karyawan adalah setiap orang yang bekerja dengan menjual tenaganya (fisik dan pikiran) kepada suatu perusahaan dan memperoleh balas jasa yang sesuai dengan perjanjian. Sedangkan menurut kamus besar bahasa Indonesia karyawan merupakan orang yang bekerja pada suatu lembaga (kantor, perusahaan, dsb) dengan mendapatkan gaji (upah) Rekrutmen Karyawan

Menurut Sutrisno (2009:45) rekrutmen merupakan suatu proses mencari, mengadakan, menemukan, dan menarik para pelamar untuk dipekerjakan dalam suatu organisasi.

\section{Devinisi Motivasi kerja}

Hasibuan (2005:141) bahwa: motivasi kerja adalah hal yang menyebabkan, menyalurkan, dan mendukung perilaku manusia, supaya mau bekerja giat dan antusias mencapai hasil kerja yang optimal.

\section{Definisi Motivasi}

Menurut Sutrisno (2009:115) motivasi adalah suatu faktor yang mendorong seseorang untuk melakukan suatu aktivitas tertentu.

\section{E. Definisi Motivasi Menurut Islam}

Menurut Rivai (2009:181) pada dasarnya motivasi memotivasi karyawan untuk bekerja keras sehingga dapat mencapai tujuan mereka. Hal ini meningkatkan produktivitas kerja karyawan sehingga dapat mencapai tujuan mereka.

\section{F. Faktor-faktor yang Mempengaruhi Motivasi}

Sedangkan faktor-faktor yang mempengaruhi motivasi dalam Islam Menurut Rivai (2009:860-861) pada dasarnya motivasi memotivasi karyawan untuk bekerja keras sehingga dapat mencapai tujuan mereka. Hal ini meningkatkan produktivitas kerja karyawan sehingga dapat mencapai tujuan perusahaan. Sumber motivasi ada tiga faktor:

1. Kemungkinan untuk berkembang

2. Jenis pekerjaan

3. Apakah mereka dapat merasa bangga menjadi bagian dari perusahaan.

\section{G. Teori motivasi}

Abraham H. Maslow dengan teori hierarkhi

Teori motivasi yang di kembangkan Maslow mengemukakan bahwa kebutuhan manusia itu dapat diklarifikasikan ke dalam lima hierarkhi kebutuhan,yaitu sebagai berikut:

1) Kebutuhan fisiologis (physiological)

Kebutuhan untuk mempertahankan hidup disebut juga Kebutuhan fisiologis 
(physiological), yaitu kebutuhan untuk mempertahankan hidup dari kematian. Keinginan untuk memenuhi kebutuhan tersebutlah yang mendorong orang untuk mengerjakan suatu pekerjaan, karena dengan bekerja itu ia mendapatkan imbalan yang di gunakan untuk pemenuhan kebutuhan. Contohnya: makan, minum, rumah dan pakaian.

2) Kebutuhan rasa aman (safety)

Kebutuhan rasa aman dan keselamatan, kebutuhan ini akan di rasa mendesak setelah kebutuhan pertama terpenuhi.upaya yang dilakukan oleh perusahaan untuk memenuhi kebutuhan dan keamanan ini dapat melalui:

a) Selalu memberikan informasi agar para karyawan dalam bekerja bersikap hati-hati dan waspada,

b) Menyediakan tempat kerja aman dari keruntuhan, kebakaran, dan sebagainya,

c) Memberikan perlindungan asuransi jiwa, terutama bagi karyawan yang bekerja pada tempat rawan kecelakaan,

d) Memberikan jaminan kepastian kerja, bahwa selama mereka bekerja dengan baik, maka tidak akan di PHK-kan, dan adanya jaminan kepastian pembinaan karir.

3) Kebutuhan hubungan sosial (affiliation) Kebutuhan ini hanya dapat terpenuhi bersama masyarakat, karena memang orang lainlah yang dapat memenuhinya, bukan diri sendiri. Contohnya: kebutuhan dicintai, disayangi, dihormati ,dihargai ,kebutuhan untuk berprestasi.

4) Kebutuhan pengakuan (esteem)
Setiap orang normal membutuhkan adanya penghargaan diri dan penghargaan prestise diri dari lingkungannya. Semakin tinggi status dan kedudukan seseorang dalam perusahaan, maka semakin tinggi pula kebutuhan akan pretise diri yang bersangkutan.

5) Kebutuhan aktualisasi diri

Kebutuhan aktulisasi diri merupakan kebutuhan yang paling tinggi. Untuk memenuhi kebutuhan puncak ini biasanya seseorang bertindak bukan atas dorongan orang lain.

\section{H. Teori Motivasi Islam}

Terdapat tiga teori motivasi dalam Islam yang dapat menjadi acuan diantaranya : Tabel 1.

Teori Motivasi Islam

\begin{tabular}{|c|c|}
\hline $\begin{array}{l}\text { Teori } \\
\text { Motivasi } \\
\text { Mursi }\end{array}$ & $\begin{array}{l}\text { 2.Motivasi } \\
\text { Psikologis } \\
\text { atau Sosial a. }\end{array}$ \\
\hline Teori & 1.The Need Theory \\
\hline & $\begin{array}{l}\text { 2.Instincts and } \\
\text { Innate Biological } \\
\text { Determinants for } \\
\text { Behaviour }\end{array}$ \\
\hline $\begin{array}{l}\text { Teori Motivasi Al } \\
\text { Ghazali }\end{array}$ & $\begin{array}{l}\text { 1.Bersifat fisik } \\
\text { 2.Bersifat }\end{array}$ \\
\hline
\end{tabular}

Sumber :Mursi (1999, 107-121), Ahmad (2007:197-198), Al- Ghazali (dalam Rivai 2009:861)

\section{METODE PENELITIAN}

\section{A. Pendekatan Penelitian}

Pendekatan yang digunakan dalam penelitian ini adalah kualitatif deskriptif. 
Penelitian kualitatif melibatkan peneliti dalam setiap penelitian yang dilakukan.

\section{B. Ruang Lingkup Penelitian}

Ruang lingkup penelitian ini terbatas pada motivasi yang mendasari dalam memilih profesi sebagai karyawan di Bank Syariah X Surabaya rekrutmen tahun 2012

\section{Teknik Penentuan Informan}

Dalam penelitian ini informan didapatkan dengan menggunakan Purposive sampling yakni teknik pengambilan sampel sumber data dengan pertimbangan tertentu.

\section{Data dan Sumber Data}

Menurut Loafland dalam Moleong (2001:112), sumber utama dari penelitian kualitatif adalah kata-kata dan tindakan, dan selebihnya adalah data tambahan seperti dokumen dan lainnya. Data primer ini didapatkan melalui wawancara secara langsung dengan informan atau orang yang diwawancarai sebagai key source.

\section{E. Prosedur Pengumpulan Data}

Yin (2012:103) mengatakan ada enam sumber bukti yang dijadikan fokus bagi pengumpulan data studi kasus, yaitu:

1. Dokumen

2. Observasi langsung

3. Wawancara

4. Perangkat fisik

\section{F. Uji Validitas}

Triangulasi (Triangulation) dalam penelitian studi kasus, adalah pendekatan yang dilakukan hanya pada satu sumber tidak akan memberikan informasi yang dibutuhkan. Kunci utama dalam melakukan penelitian studi kasus adalah banyaknya sumber yang berbeda-beda namun tetap memiliki keterkaitan satu sama lain sehingga informasi yang diterima akan lebih meyakinkan dan akurat. Adapun teknik triangulasi yang digunakan adalah:

1) Triangulasi Sumber

Menurut Moleong (2005:330) triangulasi dengan sumber adalah membandingkan dan mengecek baik derajat kepercayaan suatu informasi yang diperoleh melalui waktu dan alat yang berbeda dalam penelitian kualitatif, mengecek data yang diperoleh dari seorang informan (karyawan), kemudian data tersebut diuji dengan bertanya pada informasi lain (karyawan lain) secara terus menerus sampai terjadi kejenuhan data, artinya sampai tidak ditemukan lagi data baru.

2) Triangulasi dengan Metode

Triangulasi dengan metode menurut Patton dalam Moleong (2006:331) adalah:

a) Pengecekan derajat kepercayaan penemuan hasil penelitian beberapa teknik pengumpulan data, peneliti mengecek data atau informasi yang diperoleh melalui metode wawancara kemudian data tersebut dicek melalui observasi (pengamatan) atau dokumentasi, dan begitu juga sebaliknya.

b) Pengecekan derajat kepercayaan beberapa sumber data dengan metode yang sama, peneliti mengecek data atau informasi yang diperoleh melalui wawancara dengan seorang informan. Kemudian data yang diperoleh tersebut 
dicek pada informan yang bersangkutan pada waktu yang berbeda.

3) Triangulasi dengan Teori

Triangulasi dengan teori menurut Lincoln dan Guba dalam Moleong (2005:331) adalah berdasarkan anggapan bahwa fakta fakta tidak dapat diperiksa derajat kepercayaannya dengan salah satu teori. Peneliti melakukan kesesuaian motivasi karyawan bekerja dengan salah satu teori yang telah dipilih oleh peneliti.

Dari tabel 2. dapat disimpulkan bahwa keseluruhan dari informan memiliki motivasi Untuk memenuhi kebutuhan hidup, pertimbangan rotasi perpindahan yang hanya dalam ruang lingkup jawa timur merupakan merupakan motivasi utama dari seluruh informan, sedangkan keinginan untuk berkembang, kepastian jenjang karir, dan merasa memiliki tanggung jawab akhirat merupakan motivasi lain yang mendominasi informan sehingga mereka termotivasi untuk memilih profesi sebagai karyawan di Bank Syariah X Surabaya. Semua informan merasa iklas mendaftar bekerja di Bank Syariah X Surabaya tanpa ada paksaan dari pihak manapun.
Tabel 2.

Klarifikasi Motivasi memilih profesi sebagai karyawan Bank Syariah X Surabaya menurut Teori Ahmad

\begin{tabular}{|c|c|c|c|c|c|c|}
\hline $\begin{array}{l}\text { Motivasi memilih profesi sebagai } \\
\text { karyawan Bank Syariah X Surabaya }\end{array}$ & 产 & $\frac{8}{5} \frac{8}{0}$ & & 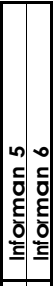 & : & 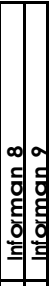 \\
\hline 1.The Need Theory & & & & & & \\
\hline untuk memenuhi kebutuhan hidup & & & & & & \\
\hline Mengharapkangaji yang lebih tinggi & & & & & & \\
\hline $\begin{array}{l}\text { 2.Instincts and Innate Biological } \\
\text { Determinants for Behaviour }\end{array}$ & & & & & & \\
\hline $\begin{array}{l}\text { Cint Jawa limur mengembangkan } \\
\text { Jawa imur dari sisi syariah }\end{array}$ & & & & & & \\
\hline $\begin{array}{l}\text { Karena sesuai dengan latar } \\
\text { belakang pendidikan sebelunya }\end{array}$ & & & & & & \\
\hline $\begin{array}{l}\text { Sebelumnya pernah bekerja } \\
\text { diperbankan }\end{array}$ & & & & & & \\
\hline Ingin bekerja sebagai karyawan & & & & 1 & & \\
\hline $\begin{array}{l}\text { Ingin tau mekanisme di } \\
\text { perbankan syariah }\end{array}$ & & & & & & \\
\hline tertarik di bisnis & & & & & & \\
\hline 3.Incentives (External Stimuli) & & & & & & \\
\hline $\begin{array}{l}\text { Rotas penempatan yang } \\
\text { hanya wilayah Jawa Timur saja }\end{array}$ & & & & & & \\
\hline Kepastian jenjang karir & & & & 1 & & \\
\hline $\begin{array}{l}\text { Jaminan kesehatan, jaminan hari } \\
\text { tua dan jaminan lainnya }\end{array}$ & & & & & & \\
\hline Penghargaan dari lingkungan & & & & & & \\
\hline 4.Commitment (Ikhlas) & & & & & & \\
\hline $\begin{array}{l}\text { Merasa ikhlas bekeria di Bank } \\
\text { Syariah X Surabaya }\end{array}$ & & & & & & \\
\hline $\begin{array}{l}\text { Memang ingin bekerja di Bank } \\
\text { Syariah XSurabaya }\end{array}$ & & & & & & \\
\hline $\begin{array}{l}\text { Dapat mengembangkan Bank } \\
\text { Syariah X Surabaya, }\end{array}$ & & & & & & \\
\hline $\begin{array}{l}\text { Dapat lebih bermanfaat bila } \\
\text { bekerja di }\end{array}$ & & & & & & \\
\hline Tidak mau pindah di konvensional & & & & & & \\
\hline $\begin{array}{l}\text { Tidak mau pindah ke bank yang } \\
\text { murni syariah bila swasta }\end{array}$ & & & & & & \\
\hline 5.Motivated Personality & & & & & & \\
\hline a.Nafs Ammarah & & & & & & \\
\hline $\begin{array}{l}\text { Tidak percaya diri karena } \\
\text { punya pengalaman buruk } \\
\text { terdahulu }\end{array}$ & & & & & & \\
\hline
\end{tabular}

\section{G. Temuan Lain}

Terdapat beberapa temuan lain dalam penelitian yang dilakukan peneliti selama penelitian diantaranya adalah karyawan yang sebelumya pernah 
memiliki latar belakang pendidikan di bidang perbankan syariah atau sebelumnya pernah bekerja di perbankan syariah lebih memiliki motivasi dan komitmen yang besar ketika bekerja di Bank Syariah X Surabaya dan mereka pada umumnya memiliki prestasi kerja lebih baik di bandingkan dengan karyawan lain yang tidak memiliki latar belakang pendidikan di bidang perbankan syariah dan pengalaman bekerja di perbankan syariah sebelumnya, hal ini menyebabkan adanya peningkatan jenjang karir yang lebih cepat pada karyawan yang sebelumnya memiliki latar belakang pendidikan di bidang perbankan syariah dan pernah mempunyai pengalaman bekerja di perbankan syariah sebelumnya.

\section{H. Keterbatasan Penelitian}

Penelitian ini hanya meneliti tentang motivasi memilih profesi sebagai karyawan di Bank Syariah X Surabaya sesuai dengan teori motivasi Ahmad. Informan yang di pilih dalam penelitian ini adalah karyawan Bank Syariah $X$ Surabaya Rekrutmen 2012, hal ini karena karyawan rekrutmen tahun 20072011 merupakan karyawan yang mendaftar di Bank X Surabaya terapi ditempatkan atau ditugaskan di Bank Syariah $X$ Surabaya sehingga mereka tidak memiliki motivasi secara langsung melamar di Bank Syariah $X$ Surabaya. Peneliti menggunakan nama " Bank Syariah X Surabaya" karena peneliti melakukan wawancara tanpa mendapat ijin dari bank yang bersangkutan, hal ini karena informan merasa enggan mengutarakan motivasi yang sebenarnya apabila peneliti meminta ijin penelitian pada bank yang bersangkutan. Triangulasi yang di gunakan pada penelitian ini hanya triangulasi sumber dan Triangulasi dengan Metode Pengecekan derajat kepercayaan beberapa sumber data dengan metode yang sama.terdapat banyak teori motivasi dalam Islam tetapi peneliti hanya terbatas motivasi Islam menurut teori Ahmad (2007:199-202). Penelitian ini hanya terbatas meneliti tentang motivasi memilih profesi sebagai karyawan di Bank Syariah X Surabaya pada saat perekrutan karyawan dan tidak meneliti motivasi kerja karyawan serta kinerja dari karyawan di Bank Syariah X Surabaya.

\section{KESIMPULAN DAN SARAN}

\section{A. Simpulan}

1. Untuk memenuhi kebutuhan hidup, pertimbangan rotasi perpindahan yang hanya dalam ruang lingkup jawa timur merupakan merupakan motivasi utama dari seluruh informan, sedangkan keinginan untuk berkembang, kepastian jenjang karir, dan merasa memiliki tanggung jawab akhirat merupakan motivasi lain yang mendominasi informan sehingga mereka termotivasi untuk memilih profesi sebagai karyawan di Bank Syariah $X$ Surabaya. Semua informan merasa iklas mendaftar bekerja di Bank Syariah $X$ Surabaya tanpa ada paksaan dari pihak manapun.

2.

Motivasi

untuk 
memenuhi kebuhuhan hidup di klarifikasikan ke dalam teori ahmad yaitu (The Need Theory) hal ini karena memang tujuan utama informan bekerja adalah untuk memenuhi kebutuhan hidupnya, motivasi pertimbangan rotasi perpindahan yang hanya dalam ruang lingkup jawa timur dan kepastian jenjang karir di klarifikasikan ke dalam teori ahmad yaitu Incentives (External Stimuli) hal ini menjadi pertimbangan utama dengan alasan informan tidak ingin jauh dari kelvarga jika berpindah tempat kerja serta adanya kepastian peningkatan jabatan dan kejelasan kerja informan, keingingan untuk berkembang di klarifikasikan ke dalam teori ahmad yaitu Nafs Lawwamah, Merasa memiliki tanggung jawab akhirat di klarifikasikan dalam teori ahmad Nafs Mutmainnah, hal ini memotivasi karyawan untuk tidak mencari keuntungan di dunia saja tetapi juga rasa tanggung jawab di akhirat. Rasa iklas mendaftar tanpa ada paksaan di klarifikasikan ke dalam teori ahmad yaitu Commitment (Ikhlas)

\section{B. SARAN}

1. Bagi informan, dari hasil penelitian ini hendaknya informan dapat meningkatkan komitmennya bekerja di Bank Syariah X Surabaya dengan menolak bila di tawari berpindah di bank konvensional karena tidak sesuai dengan syariat islam, Bagi Bank Syariah $X$ Surabaya untuk dapat meningkatkan motivasi dan kepuasan kerja dari karyawan sehingga karyawan dapat meningkatkan kinerjanya.

2. Bagi penelitian selanjutnya, diharapkan penelitian ini dapat digunakan sebagai acuan atau bahan referensi bagi penelitian selanjutnya, khususnya dalam ruang lingkup motivasi . Disamping itu, tanpa mengubah tema dari penelitian ini, disarankan agar penelitian selanjutnya dapat memperluas cakupan ataupun jumlah informan, sehingga digunakanlah teknik kuantitatif dengan analisis faktor untuk mengetahui motivasi apa yang paling utama dan mendominasi informan (karyawan bank syariah) dalam memilih profesi sebagai karyawan di bank syariah .

\section{DAFTAR PUSTAKA}

Ahmad, Khaliq. 2007. Management From Islamic Perspective Principles and Practices. Edisi Kedua. International Islamic University Malaysia: Research Center.

Malayu, S.P. Hasibuan 2007. Manajemen Sumber Daya Manusia, cetakan kesembilan, Jakarta : PT Bumi Aksara.

Mursi, Abdul Hamid. 1999. SDM yang Produktif : Pendekatan Al Quran dan Sains. Edisi Cetakan Keempat. Jakarta: Gema Insani Press.

Rivai, Veithzal. 2009. Islam Human Capital dari teori dan praktik manajemen sumber daya 
manusia. Edisi Pertama. Jakarta:

Rajawali Pers

Setiadi, J. Nugroho. 2010. Perilaku Konsumen. Edisi Revisi. Jakarta: Kencana.

Silalahi, Gabriel Amin. 2003. Metodologi Penelitian dan Studi Kasus. Sidoarjo: Citra Media.

Sugiyono. 2011. Metodologi Penelitian Kuantitatif Kualitatif dan R\&D. Bandung: ALFABETA.

Sutrisno, Edy. 2009. Manajemen Sumber Daya Manusia. Edisi Pertama. Jakarta: Kencana

Yin, Robert K. 2009. Case Study Research: Design and Methods. Edisi Keempat. United States of America: SAGE Publications, Inc 